\title{
Pediatric Acute Kidney Injury: Focusing on Diagnosis and Management
}

\author{
Myung Hyun Cho, M.D. \\ Department of Pediatrics, Hallym \\ University Sacred Heart Hospital, \\ Anyang, Republic of Korea
}

Corresponding author:

Myung Hyun Cho, M.D.

Address: Department of Pediatrics, Hallym

University Sacred Heart Hospital, 22

Gwanpyeong-ro 170 beon-gil, Dongan-

gu, Anyang 14068, Korea

Tel: $+82-31-380-3730$

Fax: $+82-31-380-1900$

E-mail:dong82dong82@naver.com

Received: 6 March 2020

Revised: 1 April 2020

Accepted: 9 April 2020
Acute kidney injury (AKI) is common in critically ill children, and is associated with increased mortality and long-term renal sequelae. The definition of pediatric AKI was standardized based on elevation in serum creatinine levels or decrease in urine output; accordingly, epidemiological studies have ensued. Although new biomarkers appear to detect AKI earlier and predict prognosis more accurately than traditional markers, they are not frequently used in clinical setting. There is no validated pharmacological intervention for AKI, so prevention and early detection are the mainstays of treatment. For high risk or early stage AKI patients, optimization of volume status and blood pressure, avoidance of nephrotoxins, and sufficient nutritional support are necessary, and have been demonstrated to be effective in preventing the occurrence of AKI and improving prognosis. Nevertheless, renal replacement therapy is needed when conservative care fails.

Key words: Acute kidney injury, Critical care, Pediatrics

\section{Introduction}

Acute kidney injury (AKI) is characterized by an abrupt deterioration of kidney function, and is common in critically ill children and adults. It occurs in approximately $30 \%$ of pediatric intensive care unit (PICU) ${ }^{1}$. Pediatric AKI has been associated with higher morbidity and mortality after adjustment for other risk factors ${ }^{1)}$, and is a risk factor for hypertension and chronic kidney disease (CKD) in the long term ${ }^{2,3)}$. Recently, many studies have been conducted in the field of pediatric AKI following adult studies and have prompted new interest. This review summarizes pediatric AKI, with a focus on diagnosis and management.

\section{Definition of AKI}

In 2012, the Kidney Disease: Improving Global Outcomes (KDIGO) criteria were established, and provided a standardized definition of AKI in children and adults ${ }^{4}$. It was characterized by elevation in serum creatinine levels and/ or decrease in urine output, based on the previously well-known, Risk, Injury, Failure; Loss, End-Stage Renal Disease (RIFLE) and Acute Kidney Injury Network (AKIN) criteria (Table 1) ${ }^{4}$. The severity of AKI is staged according 
to the amplitude of serum creatinine elevation form baseline value or the duration of compromised urine output.

Physicians sometimes, however, experience difficulty in diagnosing and staging AKI using the KDIGO definition. Many patients exhibit elevated serum creatinine levels without previous measurement. It is not integrated to set baseline value without available measurement data within $48 \mathrm{~h}$, as specified by the KDIGO criteria. Some have used the lowest serum creatinine level measured before or after $\mathrm{AKI}$ as a baseline value. Others propose that the baseline serum creatinine level can calculate backward using an estimated glomerular filtration rate (eGFR) of 100-120 mL/ $\min / 1.73 \mathrm{~m}^{2}$, assuming that previous kidney function was normal $^{5)}$.

For neonates, the neonatal modified KDIGO definition was used in a recent large cohort (Table 1$)^{6,7)}$. Although it is based on a modification of the KDIGO definition, it is different with urinary output checked in $24 \mathrm{~h}$ blocks. Moreover, the baseline value is the lowest previous serum creatinine level because serum creatinine, which reflects maternal creatinine in the first few days, declines physiologically within weeks of life at a rate that varies with gestational age $^{8,9)}$.

\section{AKI biomarkers}

Serum creatinine is currently widely used as a biomarker for AKI; however, it has some limitations. It is insensitive to small changes in GFR, and is not a real-time indicator. It may not change until up to $50 \%$ of kidney function is lost ${ }^{10)}$, and rise up to $72 \mathrm{~h}$ after an insult. Furthermore, its concentration is affected by age, sex, muscle mass, and volume status ${ }^{11)}$. For two decades, many researchers have been searching new biomarkers that are rapid, sensitive, specific, inexpensive, noninvasive, and unaffected by clinical factors ${ }^{12}$. Cystatin $C$, neutrophil gelatinase-associated lipocalin (NGAL), kidney injury molecule-1, N-acetyl- $\beta$ D-glucosaminidase, interleukin-18, liver-type fatty acidbinding protein, cycle arrest markers, and BPI containing family A member 2 have been evaluated. These appear to detect AKI earlier and predict prognosis more accurately than serum creatinine levels ${ }^{12)}$.

Serum cystatin C is produced by all nucleated cells and, is therefore, unaffected by clinical factors ${ }^{13)}$. Its level rises earlier (12-24 h after insult) than that of serum creatinine ${ }^{14)}$. In studies involving specific pediatric populations (children who underwent cardiac surgery, treated with aminoglycoside or contrast agent, and preterm infants with respiratory distress syndrome), it predicted AKI earlier than serum creatinine level, predicted persistent AKI, and showed greater sensitivity and specificity ${ }^{14-17)}$. Its disadvantage is that it is affected by high-dose corticosteroids, inflammation, and systemic diseases ${ }^{18)}$. NGAL, a proximal tubular protein, is the most rapid predictive biomarker, and is elevated $<2 \mathrm{~h}$ after insult ${ }^{19)}$. Studies investigated NGAL in pediatrics have mainly involved patient undergoing cardiac surgery, and have reported that elevation of urinary NGAL

Table 1. Definitions and Staging of Kidney Disease: Improving Global Outcomes (KDIGO) and Neonatal Modified KDIGO Criteria for Acute Kidney Injury

\begin{tabular}{|c|c|c|c|c|}
\hline \multirow{2}{*}{ Stage } & \multicolumn{2}{|l|}{ Pediatric KDIGO criteria } & \multicolumn{2}{|c|}{ Neonatal modified KDIGO criteria } \\
\hline & Serum creatinine & Urine output & Serum creatinine & Urine output \\
\hline 1 & $\begin{array}{l}\text { 1.5-1.9 times baseline within } 7 \text { days } \\
\text { OR } \\
\geq 0.3 \mathrm{mg} / \mathrm{dL} \text { increase within } 48 \mathrm{~h}\end{array}$ & $<0.5 \mathrm{~mL} / \mathrm{kg} / \mathrm{h}$ for $6-12 \mathrm{~h}$ & $\begin{array}{l}\text { 1.5-1.9 times baseline } \mathrm{F}^{*} \text { within } 7 \text { days } \\
\text { OR } \\
\geq 0.3 \mathrm{mg} / \mathrm{dL} \text { increase within } 48 \mathrm{~h}\end{array}$ & $\begin{array}{c}>0.5 \text { and } \leq 1 \mathrm{~mL} / \mathrm{kg} / \mathrm{h} \\
\text { over } 24 \mathrm{~h}\end{array}$ \\
\hline 2 & 2.0-2.9 times baseline & $<0.5 \mathrm{~mL} / \mathrm{kg} / \mathrm{h}$ for $\geq 12 \mathrm{~h}$ & 2.0-2.9 times baseline* & $\begin{array}{c}>0.3 \text { and } \leq 0.5 \mathrm{~mL} / \mathrm{kg} / \mathrm{h} \\
\text { over } 24 \mathrm{~h}\end{array}$ \\
\hline 3 & $\begin{array}{c}\geq 3.0 \text { times baseline } \\
\text { OR } \\
\text { Increase in serum creatinine to } \geq 4.0 \mathrm{mg} / \mathrm{dL} \\
\text { OR } \\
\text { Initiation of renal replacement therapy } \\
\text { OR } \\
\text { Decrease in eGFR to }<35 \mathrm{~mL} / \mathrm{min} \text { per } 1.73 \mathrm{~m}^{2}\end{array}$ & $\begin{array}{c}<0.3 \mathrm{~mL} / \mathrm{kg} / \mathrm{h} \text { for } \geq 24 \mathrm{~h} \\
\text { OR } \\
\text { Anuria for } \geq 12 \mathrm{~h}\end{array}$ & $\begin{array}{c}\qquad 3.0 \text { times baseline } \\
\text { OR } \\
\text { Increase in serum creatinine to } \geq 2.5 \mathrm{mg} / \mathrm{dL} \\
\text { OR } \\
\text { Initiation of renal replacement therapy }\end{array}$ & $\leq 0.3 \mathrm{~mL} / \mathrm{kg} / \mathrm{h}$ over $24 \mathrm{~h}$ \\
\hline
\end{tabular}

*Baseline serum creatinine is the lowest previous value. Abbreviation: eGFR, estimated glomerular filtration rate. 
was associated with poor prognosis ${ }^{20,21)}$. Urinary NGAL increases during urinary tract infection, sepsis, and CKD regardless of $\mathrm{AKI}^{22)}$. A combination of two cell-cycle arrest markers urinary tissue inhibitor of metalloproteinase- 2 and insulin-like growth factor-binding protein 7 demonstrated high sensitivity (90\%) and low specificity (49\%) in critically ill adults ${ }^{23)}$, and was approved by the United States Food and Drug Administration for use in adults. A few studies have shown that it has good diagnostic performance in pediatric, and neonatal $\mathrm{AKI}^{24,25)}$.

Despite the excellent performance of new biomarkers, they are not frequently used in clinical setting due to several concerns. First, they were validated for specific etiologies of AKI, such as pediatric patients undergoing cardiac surgery, and their efficacy cannot be reproduced in AKIs of different etiologies ${ }^{12)}$. Moreover, they are also elevated in other clinical conditions, such as inflammation ${ }^{12)}$. Large prospective studies investigating and validating the clinical utility of these biomarkers, therefore, is warranted.

\section{Incidence}

Two large, multinational epidemiological studies have been published in the pediatric and neonatal areas ${ }^{1,7)}$. The Assessment of Worldwide Acute Kidney Injury, Renal Angina, and Epidemiology (AWARE) study described the epidemiology of AKI in 4,683 pediatric patients (age range 3 months to 25 years) who were admitted to the PICU ${ }^{1)}$. It reported that AKI developed in 26.9\% of patients and KDIGO stage 2 or 3 AKI in 11.6\% within 7 days of PICU admission ${ }^{1)}$. The Assessment of Worldwide Acute Kidney injury Epidemiology in Neonates (AWAKEN) study described neonatal AKI in the neonatal ICU, and reported a prevalence similar to that of the AWARE study. The incidence of AKI was $29.9 \%$, with $13.9 \%$ reaching AKI stage 1 , $7.1 \%$ reaching AKI stage 2 , and $8.9 \%$ reaching AKI stage $3^{7)}$. The incidence outside the ICU varies across medical centers. To our knowledge, there have been no large-scale studies investigating AKI in non-critically ill children in Korea.

\section{Outcomes}

In the pediatric literature, $\mathrm{AKI}$ is consistently associated with poor outcomes, similar to adults. Many studies have demonstrated that AKI is an independent risk factor for prolonged stay in the PICU, longer duration of mechanical ventilation, and increased mortality among critically ill children ${ }^{1,26,27)}$. In addition, several observational studies have reported a high prevalence of CKD, hypertension, and proteinuria among AKI survivors ${ }^{28-30)}$. Neonatal AKI is also a risk factor for mortality ${ }^{7}$. There have been no sufficiently large follow-up studies evaluating the relationship between neonatal AKI and long-term renal insufficiency. However, small observational studies have reported a high prevalence of CKD, and proteinuria in survivors of neonatal $\mathrm{AKI}^{29,31)}$.

\section{Management}

\section{Risk factors and prevention}

There are no effective medications for established AKI. Therefore, prevention and early detection are the mainstays of management. Monitoring high-risk patients and reducing additional risk factors can prevent the occurrence of AKI and improve outcomes. Prematurity, and chronic diseases such as CKD render the host susceptible to AKI, and events such as volume depletion, exposure to nephrotoxins, sepsis, major surgery, and critical illness lead to AKI 4) The renal angina index was proposed to predict $\mathrm{AKI}$ in critically ill children on the basis of subtle kidney injury (changes in estimated creatinine clearance or fluid overload) and patient risk factors (ICU admission, stem cell transplantation, ventilation and inotropy) ${ }^{32)}$.

Despite its importance, physicians often do not devote attention to the accumulation of risk factors and early decline of kidney function as they perform or attend to other important aspects of care ${ }^{33)}$. Recently, a system using electronic health records was implemented and helped physicians detect AKI early and mitigate the influence of risk factors $^{34)}$. The system electronically flags high-risk patients to the medical team in near real-time. As such, the medical team does not miss high-risk patients and monitors them carefully. It has been shown to improve the rate of recovery from $\mathrm{AKI}^{35)}$. In the pediatric literature, this system was 
developed to screen children who experienced multiple nephrotoxin exposures, which prompted clinicians to monitor more closely for the development of AKI. It demonstrated a positive effect in decreasing exposure to multiple nephrotoxins and, finally, AKI events ${ }^{36)}$.

\section{Supportive care}

Supportive care comprises optimization of volume status, blood pressure, avoidance of nephrotoxic agents, and nutritional support. It is important to maintain adequate renal perfusion through fluid and hemodynamic management ${ }^{37}$. Volume status should be optimal (i.e., not excessive, not insufficient). The medical history and symptoms are important to evaluate volume status. Body weight, fluid intake, urine and stool output, and vital signs should be monitored daily, and lung sound and lower extremity edema should be checked $^{38,39)}$. Serum chemistries and chest X-ray are also useful. Although volume depletion is a well-known risk factor, volume overload is associated with poor prognosis ${ }^{40)}$. Fluid accumulation in the acute phase, which is common in the PICU, is associated with high mortality in critically ill patients ${ }^{40,41)}$. The pediatric literature suggests that $10-20 \%$ fluid overload is a critical threshold at which outcomes are negatively impacted ${ }^{41,42}$. Administration of optimal fluid amount is crucial. Patients with a normal intravascular volume should initially be limited to insensible losses $\left(400 \mathrm{~mL} / \mathrm{m}^{2} / \mathrm{d}\right)$ plus an amount of fluid equal to the urine output and extrarenal loss ${ }^{38)}$. Noticeable hypervolemic patients require further fluid restriction, omitting the replacement of insensible fluid losses, urine output, and extrarenal losses while considering adequate nutritional support ${ }^{38)}$. Diuretics therapy, especially loop diuretics, should be considered for hypervolemic patients. The pediatric literature shows that clinicians should consider initiating renal replacement therapy (RRT) at a fluid overload of $>20 \%$, while a fluid overload $10-20 \%$ requires further evaluation ${ }^{42)}$.

The proper type of fluid should be administered to prevent volume depletion. Crystalloids are the preferred solutions because data supporting the routine use of colloids for volume resuscitation are lacking ${ }^{43}$. Colloid solution was not superior to crystalloid in terms of the prevention of AKI in children who underwent cardiac surgery ${ }^{44}$. Among crystalloids, some studies have reported that a balanced solution, such as Ringer's lactate solution, is superior to normal saline ${ }^{45}$. Balanced solutions are defined as intravenous fluids having an electrolyte composition close to that of plasma. They have low chloride content of about 100$110 \mathrm{mmol} / \mathrm{L}$, which is the most altered in normal saline as compared to plasma ${ }^{46,47)}$. Normal saline, which is hyperchloremic, can cause hyperchloremic metabolic acidosis, contributing to impaired recovery and poor clinical outcomes $^{48)}$. Three recent large prospective studies have reported conflicting results ${ }^{49-51)}$; as such, debate regarding which solution is best among crystalloids continues.

Maintaining optimal blood pressure is crucial, although there is no currently definitive target value for pediatric AKI. For patients with hypotension, fluid resuscitation is initially considered if hypotension is due even partially to hypovolemia ${ }^{18)}$. Norepinephrine is recommended if hypovolemia is not suspected ${ }^{52)}$. High blood pressure in patients with AKI is mostly due to volume overload or disturbed renin-angiotensin axis ${ }^{22}$. Diuretics are attempted first unless patients exhibit signs of intravascular depletion ${ }^{22}$.

Nephrotoxin exposure is one of the most common causes of AKI in hospitalized children ${ }^{53)}$. Critically ill patients who are at high risk for AKI have the opportunity to be administered nephrotoxic mediations. Amphotericin, aminoglycoside, vancomycin, nonsteroidal anti-inflammatory drugs, angiotensin-converting enzyme inhibitors, angiotensin receptor blockers, calcineurin inhibitors, cisplatin, and methotrexate are well-known nephrotoxins ${ }^{18}$. Clinicians must balance the therapeutic benefits versus the risk for nephrotoxicity. If the use of nephrotoxic medications is inevitable, their dosage or dosing interval should be adjusted and monitored to reduce renal toxicity. Drug levels should be measured, if possible, and adjusted accordingly. If not possible, medications should be adjusted based on eGFR. Be aware that eGFR does not account for real-time renal function in $\mathrm{AKI}^{22)}$. Contrast agent used for computed tomography and angiography are nephrotoxic. Contrastinduced AKI is common in children ${ }^{54)}$, and risk depends on the contrast agent dosage and type. Angiography requires more attention because it requires more contrast agent than computed tomography. High-osmolality contrast agent carries a higher risk for AKI, but have been replaced by low-osmolality contrast agents, which have a lower risk ${ }^{55)}$. Nevertheless, patients with a GFR $<60 \mathrm{~mL} /$ 
$\mathrm{min} / 1.73 \mathrm{~m}^{2}$ or at high risk for AKI should be prepared before exposure ${ }^{22)}$. The key preventive measure is hydration. An isotonic crystalloid solution at $1 \mathrm{~mL} / \mathrm{kg} / \mathrm{h}$ should be administered intravenously for 12 hours before and after the procedure ${ }^{18)}$. If contrast agent should be administered urgently, $3 \mathrm{~mL} / \mathrm{kg} / \mathrm{h} 1 \mathrm{~h}$ before and 6-9 mL/kg over $4-6 \mathrm{~h}$ after the procedure should be administered ${ }^{18)}$. In addition, nephrotoxins should be discontinued for $>24$ h before the procedure $^{18)}$. The use of N-Acetylcysteine (NAC) will be discussed below.

Nutritional support is important for improving outcomes in children with AKI. For critically ill children with AKI, nutritional requirements should be individualized and assessed frequently ${ }^{56)}$. In general, $120-130 \%$ of basal calories needs, and $2-3 \mathrm{~g} / \mathrm{kg} / \mathrm{day}$ of protein should be provided $^{56)}$, and hyperglycemia should be avoided ${ }^{57)}$.

\section{Pharmacological treatment}

Many researchers have investigated candidate medications to prevent and treat AKI. Anti-inflammatory, antioxidative and antiapoptotic interventions are representative examples; however, their yield remains insignificant. Although a few medications have demonstrated effectiveness in certain situations, most have yielded negative or conflicting results. Medications advocated in the past were not proven to be effective. The KDIGO guideline recommend NAC to prevent contrast-induced AKI in high-risk patients ${ }^{4)}$. However, two large, well-designed studies reported no benefit of NAC in reducing the incidence of contrast-induced $\mathrm{AKI}^{58,59)}$. Diuretics are not recommended for the prevention of AKI because their use does not alter outcomes in those with established $\mathrm{AKI}^{60)}$. Diuretics should be used only to control fluid overload. Low-dose dopamine and fenoldopam did not have a positive effect on protection against $\mathrm{AKI}^{61,62)}$. Perioperative statins did not reduce the incidence of AKI among patients undergoing cardiac surgery $^{63)}$. Even now, candidate medicines, such as recombinant alkaline phosphate, costimulatory molecule CD28 receptor antagonist, p53 small interfering RNAs, and mesenchymal stem cells, are under consideration ${ }^{18)}$. To establish the basis for routine clinical use of new medications, additional multicenter, high-quality trials are warranted.

\section{RRT}

$\mathrm{RRT}$ is required when conservative care fails. Indications for RRT include fluid overload (severe hypertension or pulmonary edema), severe hyperkalemia, metabolic acidosis, and severe uremia ${ }^{64)}$. The optimal timing of RRT initiation remains controversial. A recent meta-analysis of randomized controlled trials revealed that early initiation of RRT does not reduce mortality when compared with standard or late initiation in adults ${ }^{65)}$. Although one investigation involving pediatric patients demonstrated that early initiation improved mortality in cardiac surgery patients ${ }^{66)}$, it was small and retrospective in design; thus, more studies are needed. RRT modalities for AKI have begun with peritoneal dialysis and hemodialysis, and are now expanding to continuous renal replacement therapy (CRRT). We believe that all of these modalities represent viable management options in pediatric $\mathrm{AKI}^{67)}$. There is no definite evidence that one dialysis modality is superior to another in terms of outcomes in $\mathrm{AKI}^{68,69)}$. The modality should be determined according to the patient characteristics, institutional resources, and expertise ${ }^{69)}$. Each modality has advantages and disadvantages. Peritoneal dialysis can be used in small children such as preterm infants, but removes fluid and waste slowly and unpredictably ${ }^{67)}$. Hemodialysis removes toxins rapidly, but is dangerous for small children and hemodynamically unstable patients ${ }^{67)}$; additionally, it requires expertise. Currently, CRRT becomes the preferred modality in developed countries as improvement of equipment ${ }^{69)}$. CRRT facilitates hemodynamic stability and make it possible to use them in small children, such as neonates. New devices, such as the Cardio-Renal Pediatric Dialysis Emergency Machine, and Newcastle Infant Dialysis and Ultrafiltration System, have provided promising results for the treatment of neonates requiring $\mathrm{RRT}^{70,71)}$. However, the device should be operated in the PICU, so that children must endure anxiety about being separated from their parents during treatment.

\section{Conclusion}

AKI has attracted attention because of its high prevalence and association with poor outcomes. Many studies have been conducted to identify new biomarkers and effective 
pharmacological interventions, and significant improvements have been achieved. Unfortunately, however, not many have been applied in actual clinical practice. Considering the gap between research achievements in adults and children, pediatric nephrologists have much to contribute to developments in understanding and treating AKI.

\section{Funding}

This research did not receive any specific grant from funding agencies in the public, commercial, or not-forprofit sectors.

\section{ORCID}

Myung Hyun Cho https://orcid.org/0000-0002-32373173.

\section{Conflicts of interest}

No potential conflict of interest relevant to this article was reported.

\section{References}

1. Kaddourah A, Basu RK, Bagshaw SM, Goldstein SL. Epidemiology of Acute Kidney Injury in Critically III Children and Young Adults. N Engl J Med 2017;376:11-20.

2. Madsen NL, Goldstein SL, Froslev T, Christiansen CF, Olsen M. Cardiac surgery in patients with congenital heart disease is associated with acute kidney injury and the risk of chronic kidney disease. Kidney Int 2017;92:751-6.

3. Benisty K, Morgan C, Hessey E, Huynh L, Joffe AR, Garros D, et al. Kidney and blood pressure abnormalities 6 years after acute kidney injury in critically ill children: a prospective cohort study. Pediatr Res 2020.

4. Kellum JA, Lameire N. Diagnosis, evaluation, and management of acute kidney injury: a KDIGO summary (Part 1). Crit Care 2013; 17:204.

5. Zappitelli M, Parikh CR, Akcan-Arikan A, Washburn KK, Moffett BS, Goldstein SL. Ascertainment and epidemiology of acute kidney injury varies with definition interpretation. Clin J Am Soc
Nephrol 2008:3:948-54.

6. Charlton JR, Boohaker L, Askenazi D, Brophy PD, D'Angio C, Fuloria $M$, et al. Incidence and Risk Factors of Early Onset Neonatal AKI. Clin J Am Soc Nephrol 2019;14:184-95.

7. Jetton JG, Boohaker LJ, Sethi SK, Wazir S, Rohatgi S, Soranno DE, et al. Incidence and outcomes of neonatal acute kidney injury (AWAKEN): a multicentre, multinational, observational cohort study. Lancet Child Adolesc Health 2017;1:184-94.

8. Siegel $S R, O h W$. Renal function as a marker of human fetal maturation. Acta Paediatr Scand 1976;65:481-5.

9. Jetton JG, Askenazi DJ. Update on acute kidney injury in the neonate. Curr Opin Pediatr 2012;24:191-6.

10. Bennett MR, Nehus E, Haffner C, Ma Q, Devarajan P. Pediatric reference ranges for acute kidney injury biomarkers. Pediatr Nephrol 2015;30:677-85.

11. Devarajan P. Biomarkers for the early detection of acute kidney injury. Curr Opin Pediatr 2011;23:194-200.

12. Beker BM, Corleto MG, Fieiras C, Musso CG. Novel acute kidney injury biomarkers: their characteristics, utility and concerns. Int Urol Nephrol 2018;50:705-13.

13. Grubb A, Nyman U, Bjork J, Lindstrom V, Rippe B, Sterner G, et al. Simple cystatin C-based prediction equations for glomerular filtration rate compared with the modification of diet in renal disease prediction equation for adults and the Schwartz and the Counahan-Barratt prediction equations for children. Clin Chem 2005;51:1420-31.

14. Hassinger AB, Backer CL, Lane JC, Haymond S, Wang D, Wald EL. Predictive power of serum cystatin $C$ to detect acute kidney injury and pediatric-modified RIFLE class in children undergoing cardiac surgery. Pediatr Crit Care Med 2012;13:435-40.

15. Lau L, Al-Ismaili Z, Harel-Sterling M, Pizzi M, Caldwell JS, Piccioni $M$, et al. Serum cystatin C for acute kidney injury evaluation in children treated with aminoglycosides. Pediatr Nephrol 2017;32: 163-71.

16. El-Gammacy TM, Shinkar DM, Mohamed NR, Al-Halag AR. Serum cystatin C as an early predictor of acute kidney injury in preterm neonates with respiratory distress syndrome. Scand J Clin Lab Invest 2018;78:352-7.

17. Benzer M, Alpay H, Baykan O, Erdem A, Demir IH. Serum NGAL, cystatin $C$ and urinary NAG measurements for early diagnosis of contrast-induced nephropathy in children. Ren Fail 2016;38:2734.

18. Cho MH, Kang HG. Acute kidney injury and continuous renal replacement therapy in children; what pediatricians need to know. Korean J Pediatr 2018;61:339-47.

19. Krawczeski CD, Goldstein SL, Woo JG, Wang Y, Piyaphanee N, Ma $\mathrm{Q}$, et al. Temporal relationship and predictive value of urinary acute kidney injury biomarkers after pediatric cardiopulmonary bypass. J Am Coll Cardiol 2011;58:2301-9.

20. Yoneyama F, Okamura T, Takigiku K, Yasukouchi S. Novel Urinary Biomarkers for Acute Kidney Injury and Prediction of Clinical Outcomes After Pediatric Cardiac Surgery. Pediatr Cardiol 2019. 
www.chikd.org

21. Bennett M, Dent CL, Ma Q, Dastrala S, Grenier F, Workman R, et al. Urine NGAL predicts severity of acute kidney injury after cardiac surgery: a prospective study. Clin J Am Soc Nephrol 2008;3: 665-73.

22. Roy JP, Devarajan P. Acute Kidney Injury: Diagnosis and Management. Indian J Pediatr 2019.

23. Hall PS, Mitchell ED, Smith AF, Cairns DA, Messenger M, Hutchinson $\mathrm{M}$, et al. The future for diagnostic tests of acute kidney injury in critical care: evidence synthesis, care pathway analysis and research prioritisation. Health Technol Assess 2018;22:1-274.

24. Westhoff JH, Tonshoff B, Waldherr S, Poschl J, Teufel U, Westhoff TH, et al. Urinary Tissue Inhibitor of Metalloproteinase-2 (TIMP-2) * Insulin-Like Growth Factor-Binding Protein 7 (IGFBP7) Predicts Adverse Outcome in Pediatric Acute Kidney Injury. PLoS One 2015;10:e0143628.

25. Chen J, Sun Y, Wang S, Dai X, Huang H, Bai Z, et al. The effectiveness of urinary TIMP-2 and IGFBP-7 in predicting acute kidney injury in critically ill neonates. Pediatr Res 2019.

26. Selewski DT, Cornell TT, Heung M, Troost JP, Ehrmann BJ, Lombel RM, et al. Validation of the KDIGO acute kidney injury criteria in a pediatric critical care population. Intensive Care Med 2014;40: $1481-8$.

27. Alkandari O, Eddington KA, Hyder A, Gauvin F, Ducruet T, Gottesman $\mathrm{R}$, et al. Acute kidney injury is an independent risk factor for pediatric intensive care unit mortality, longer length of stay and prolonged mechanical ventilation in critically ill children: a twocenter retrospective cohort study. Crit Care 2011;15:R146.

28. Askenazi DJ, Feig DI, Graham NM, Hui-Stickle S, Goldstein SL. 3-5 year longitudinal follow-up of pediatric patients after acute renal failure. Kidney Int 2006;69:184-9.

29. Mammen C, Al Abbas A, Skippen P, Nadel H, Levine D, Collet JP, et al. Long-term risk of CKD in children surviving episodes of acute kidney injury in the intensive care unit: a prospective cohort study. Am J Kidney Dis 2012;59:523-30.

30. Menon S, Kirkendall ES, Nguyen H, Goldstein SL. Acute kidney injury associated with high nephrotoxic medication exposure leads to chronic kidney disease after 6 months. J Pediatr 2014;165:522-7.e2.

31. Polito C, Papale MR, La Manna A. Long-term prognosis of acute renal failure in the full-term neonate. Clin Pediatr (Phila) 1998;37: 381-5.

32. Basu RK, Zappitelli M, Brunner L, Wang Y, Wong HR, Chawla LS, et al. Derivation and validation of the renal angina index to improve the prediction of acute kidney injury in critically ill children. Kidney Int 2014;85:659-67.

33. Kumar Sethi S, Agrawal G, Wazir S, Rohatgi S, lyengar A, Chakraborty R, et al. Neonatal Acute Kidney Injury: A Survey of Perceptions and Management Strategies Amongst Pediatricians and Neonatologists. Front Pediatr 2019;7:553.

34. Sutherland SM, Chawla LS, Kane-Gill SL, Hsu RK, Kramer AA, Goldstein SL, et al. Utilizing electronic health records to predict acute kidney injury risk and outcomes: workgroup statements
Cho MH • Pediatric AKI: Focusing on Diagnosis and Management

from the 15(th) ADQI Consensus Conference. Can J Kidney Health Dis 2016:3:11.

35. Park S, Baek SH, Ahn S, Lee KH, Hwang H, Ryu J, et al. Impact of Electronic Acute Kidney Injury (AKI) Alerts With Automated Nephrologist Consultation on Detection and Severity of AKI: A Quality Improvement Study. Am J Kidney Dis 2018;71:9-19.

36. Goldstein SL, Kirkendall E, Nguyen H, Schaffzin JK, Bucuvalas J, Bracke T, et al. Electronic health record identification of nephrotoxin exposure and associated acute kidney injury. Pediatrics 2013;132:e756-67.

37. Chen H, Busse LW. Novel Therapies for Acute Kidney Injury. Kidney Int Rep 2017;2:785-99.

38. Devarajan P. Acute Kidney Injury. In: Kliegman RM, ST Geme III JW, Blum NJ, Shah SS, Tasker RC, Wilson KM, et al., editors. Nelson Textbook of Pediatrics. 21 ed. Philadelphia: Elsevier, 2019:276974.

39. Claure-Del Granado R, Mehta RL. Fluid overload in the ICU: evaluation and management. BMC Nephrol 2016;17:109.

40. Wang $N$, Jiang $L$, Zhu B, Wen Y, Xi XM. Fluid balance and mortality in critically ill patients with acute kidney injury: a multicenter prospective epidemiological study. Crit Care 2015;19:371.

41. Sutherland SM, Zappitelli M, Alexander SR, Chua AN, Brophy PD, Bunchman TE, et al. Fluid overload and mortality in children receiving continuous renal replacement therapy: the prospective pediatric continuous renal replacement therapy registry. Am J Kidney Dis 2010;55:316-25.

42. Selewski DT, Goldstein SL. The role of fluid overload in the prediction of outcome in acute kidney injury. Pediatr Nephrol 2018;33: $13-24$.

43. Moore PK, Hsu RK, Liu KD. Management of Acute Kidney Injury: Core Curriculum 2018. Am J Kidney Dis 2018;72:136-48.

44. Oh HW, Lee JH, Kim HC, Kim EH, Song IK, Kim HS, et al. The effect of 6\% hydroxyethyl starch (130/0.4) on acute kidney injury in paediatric cardiac surgery: a prospective, randomised trial. Anaesthesia 2018;73:205-15.

45. Krajewski ML, Raghunathan K, Paluszkiewicz SM, Schermer CR, Shaw AD. Meta-analysis of high- versus low-chloride content in perioperative and critical care fluid resuscitation. Br J Surg 2015; 102:24-36.

46. Hoorn EJ. Intravenous fluids: balancing solutions. J Nephrol 2017; 30:485-92.

47. Langer T, Santini A, Scotti E, Van Regenmortel N, Malbrain ML, Caironi P. Intravenous balanced solutions: from physiology to clinical evidence. Anaesthesiol Intensive Ther 2015;47 Spec No:S 78-88.

48. Chowdhury AH, Cox EF, Francis ST, Lobo DN. A randomized, controlled, double-blind crossover study on the effects of 2-L infusions of $0.9 \%$ saline and plasma-lyte(R) 148 on renal blood flow velocity and renal cortical tissue perfusion in healthy volunteers. Ann Surg 2012;256:18-24.

49. Friederich A, Martin N, Swanson MB, Faine BA, Mohr NM. Normal Saline Solution and Lactated Ringer's Solution Have a Similar Ef- 
fect on Quality of Recovery: A Randomized Controlled Trial. Ann Emerg Med 2019;73:160-9.

50. Semler MW, Self WH, Wanderer JP, Ehrenfeld JM, Wang L, Byrne DW, et al. Balanced Crystalloids versus Saline in Critically III Adults. N Engl J Med 2018;378:829-39.

51. Self WH, Semler MW, Wanderer JP, Wang L, Byrne DW, Collins SP, et al. Balanced Crystalloids versus Saline in Noncritically III Adults. N Engl J Med 2018;378:819-28.

52. Joannidis M, Druml W, Forni LG, Groeneveld ABJ, Honore PM,

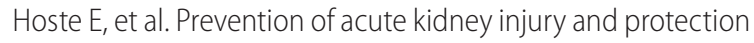
of renal function in the intensive care unit: update 2017 : Expert opinion of the Working Group on Prevention, AKI section, European Society of Intensive Care Medicine. Intensive Care Med 2017:43:730-49.

53. Hui-Stickle S, Brewer ED, Goldstein SL. Pediatric ARF epidemiology at a tertiary care center from 1999 to 2001. Am J Kidney Dis 2005;45:96-101.

54. Cantais A, Hammouda Z, Mory O, Patural H, Stephan JL, Gulyaeva $L$, et al. Incidence of contrast-induced acute kidney injury in a pediatric setting: a cohort study. Pediatr Nephrol 2016;31:1355-62.

55. Luk L, Steinman J, Newhouse JH. Intravenous Contrast-Induced Nephropathy-The Rise and Fall of a Threatening Idea. Adv Chronic Kidney Dis 2017;24:169-75.

56. Sethi SK, Maxvold N, Bunchman T, Jha P, Kher V, Raina R. Nutritional management in the critically ill child with acute kidney injury: a review. Pediatr Nephrol 2017;32:589-601.

57. Gordillo R, Ahluwalia T, Woroniecki R. Hyperglycemia and acute kidney injury in critically ill children. Int J Nephrol Renovasc Dis 2016;9:201-4.

58. Weisbord SD, Gallagher M, Jneid H, Garcia S, Cass A, Thwin SS, et al. Outcomes after Angiography with Sodium Bicarbonate and Acetylcysteine. N Engl J Med 2018;378:603-14.

59. ACT Investigators. Acetylcysteine for prevention of renal outcomes in patients undergoing coronary and peripheral vascular angiography: main results from the randomized Acetylcysteine for Contrast-induced nephropathy Trial (ACT). Circulation 2011; 124:1250-9.

60. Bagshaw SM, Delaney A, Haase M, Ghali WA, Bellomo R. Loop diuretics in the management of acute renal failure: a systematic review and meta-analysis. Crit Care Resusc 2007;9:60-8.

61. Karthik S, Lisbon A. Low-dose dopamine in the intensive care unit. Semin Dial 2006;19:465-71.

62. Bove T, Zangrillo A, Guarracino F, Alvaro G, Persi B, Maglioni E, et al. Effect of fenoldopam on use of renal replacement therapy among patients with acute kidney injury after cardiac surgery: a randomized clinical trial. Jama 2014;312:2244-53.

63. Billings FTt, Hendricks PA, Schildcrout JS, Shi Y, Petracek MR, Byrne JG, et al. High-Dose Perioperative Atorvastatin and Acute Kidney Injury Following Cardiac Surgery: A Randomized Clinical Trial. Jama 2016;315:877-88.

64. Sethi SK, Bunchman T, Raina R, Kher V. Unique considerations in renal replacement therapy in children: core curriculum 2014. Am J Kidney Dis 2014;63:329-45.

65. Pasin L, Boraso S, Tiberio I. Early initiation of renal replacement therapy in critically ill patients: a meta-analysis of randomized clinical trials. BMC Anesthesiol 2019;19:62.

66. Sanchez-de-Toledo J, Perez-Ortiz A, Gil L, Baust T, Lines-Palazon M, Perez-Hoyos S, et al. Early Initiation of Renal Replacement Therapy in Pediatric Heart Surgery Is Associated with Lower Mortality. Pediatr Cardiol 2016;37:623-8.

67. Kwiatkowski DM, Sutherland SM. Acute kidney injury in pediatric patients. Best Pract Res Clin Anaesthesiol 2017;31:427-39.

68. Nash DM, Przech S, Wald R, O'Reilly D. Systematic review and meta-analysis of renal replacement therapy modalities for acute kidney injury in the intensive care unit. J Crit Care 2017;41:138-44.

69. de Galasso L, Picca S, Guzzo I. Dialysis modalities for the management of pediatric acute kidney injury. Pediatr Nephrol 2019.

70. Ronco C, Garzotto F, Ricci Z. CA.R.PE.DI.E.M. (Cardio-Renal Pediatric Dialysis Emergency Machine): evolution of continuous renal replacement therapies in infants. A personal journey. Pediatr Nephrol 2012;27:1203-11.

71. Coulthard MG, Crosier J, Griffiths C, Smith J, Drinnan M, Whitaker $\mathrm{M}$, et al. Haemodialysing babies weighing $<8 \mathrm{~kg}$ with the Newcastle infant dialysis and ultrafiltration system (Nidus): comparison with peritoneal and conventional haemodialysis. Pediatr Nephrol 2014;29:1873-81. 